\title{
AN ANALYSIS OF THE FINANCIAL REPRESSION INDEX IN THE OECD AND BRICS COUNTRIES
}

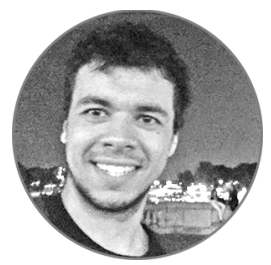

Article history:

Received 15 May 2017

Received in revised form 15 June 2017

Accepted 19 June 2017

Translated 30 August 2017

Available online 15 September 2017

JEL classification: E5, E58, E61, H27

Keywords: monetary policy, macroprudential regulation, financial repression index, Principal Component Analysis, public debt

\begin{abstract}
Importance Considering the persistence of high public debt and low growth rates, the financial repression policy remains relevant in advanced and some emerging economies. It pursues additional fiscal revenue and reducing the debt burden by artificially lowering the real interest rate, yield on deposits and government bonds. However, it becomes even more important to quantify how those measures of monetary policy influence economic growth. Making the first attempt in this respect, it is reasonable to set up a weighted index, which would imply key aspects of such policies. The article analyzes financial repression tools in 13 countries.

Objectives I set up the financial repression index and analyze what it is composed of, determining the importance of a certain tool of monetary policy as part of the general index trends.

Methods The research employs several econometric methods, with the prevalence of the Principal Component Analysis. Statistical data were brought into compliance with analyzable criteria using the $T$-test formula. To trace cross-country parallels, I use a correlation matrix.

Results The financial repression index was built. I also analyze its composition per each country and identify distinctions in applying certain financial repression tools and find a group of countries with similar characteristics. Conclusions and Relevance Most countries demonstrated a downward trend in the financial repression index. During the 2007-2009 global financial crisis and the 2014-2015 commodity price slump, the index demonstrated a spike proving that the countries resorted to financial repression tools.
\end{abstract}

๑) Publishing house FINANCE and CREDIT, 2017

The editor-in-charge of this article was Irina M. Komarova

Authorized translation by Irina M. Komarova

\section{Introduction}

Whereas both advanced and emerging economies still have to tackle the high level of public debt and low growth rates, financial repression remains relevant since it is aimed at securing additional fiscal revenue and reducing the debt burden by artificially lowering the real interest rate, yield on deposits and government bonds [1, p. 953].

${ }^{\dagger}$ For the source article, please refer to: Ахмед Абу Бакр Ф.А. Анализ структуры индекса финансовой репрессии в странах ОЭСР и БРИКС. Финансовая аналитика: проблемы и решения. 2017. Т. 10. Вып. 8. С 859-876. URL: https://doi.org/10.24891/fa.10.8.859
However, it is still important to quantify how those measures of monetary policy influence economic growth. As the first step, it is necessary to set up a weighted index, which would imply key aspects of the policy.

The structure of the financial repression index reflects which monetary regulation tools are of paramount importance in each particular country in line with its outside and domestic economic situation.

The article is intended to set up the financial repression index (FRl) and analyze its structure, identify the specifics of using certain monetary and other 
controls in each analyzable country. I also review trends in the index constituents for the 2000-2014 period in 13 member countries of the Organisation for Economic Co-operation and Development (OECD) and BRICS group.

\section{Description of the Index Constituents and Data Preparation}

Prior to the construction of the index, I describe the tools used as part of the financial repression policies.

Many researches often mix up the concepts of financial repression and macroprudential policy [2, p. 23]. For instance, if financial institutions raise their reserve requirements and purchase the more reliable government bonds instead of other securities, it can be considered as a prudent measure, from perspectives of the conventional approach to ensuring the financial stability, and a key element of financial repression [3, p. 274].

It is noteworthy that a decrease in real interest rates or bond yield coupled with their persistent positive value may be evidence of the soft monetary policy for attracting foreign investment [4, p. 39]. However, if real values of these indicators fall below zero, they can be qualified as financial repression measures.

The above situation is frequently accompanied with the terminological confusion of fiscal repression and financial repression within the same research [5, p. 664-666]. It obstructs a statistical analysis, influencing the significance and sign of a constituent in constructing an aggregate index.

Please note that the financial repression mechanism is meant to route flows of borrowings into government debt securities, which do not seem lucrative for private investors (due to the artificially lowered rate of return) $[6$, p. 144].

In other words, should the government have no financial repression option, it would have to place its public debt in the market with a higher coupon rate so to lure investors. Otherwise, it would lose some of its investment designated for purchasing more profitable instruments in the free market ${ }^{1}$.

\footnotetext{
${ }^{1}$ Hileman G. Origins and Measurement of Financial Repression: The British Case in the mid-20th Century. Financial History Workshop, Work Paper, 2016, May 27, p. 3.
}

Thus, in a proof by contradiction I define financial repression as a policy, which makes economic agents act otherwise than they would do without the policy.

For purposes of this research, I select five factors that are believed to be the most typical of financial repression.

1. Real Interest Rate $(R I R)$ is the refinancing rate ${ }^{*}$ adjusted for inflation measured with the GDP deflator.

There is a variety of tools for setting up an interest rate and its nature. For example, in some countries, the interest rate of the REPO market becomes a key rate, while, in other countries, it is the discount rate charged on mid-term loans issued to commercial banks.

The data on the indicator proceed from the World Bank database. Considering the above specifics of the interest rate formation in various countries, the data comparability is limited. If the indicator decreases, it marks a growth in financial repression. Hence, it should boost FRI.

2. Real Deposit Rate (RDR) is the inflation-specific interest rate commercial banks use to pay their depositors for deposit placements - on-call, time or savings ones.

Data on the indicator were also sourced from the World Bank database. It is worth mentioning that financial repression is also seen in case of the government limiting the yield on deposits so to urge economic agents' spending in the current period. To do this, the government can establish the threshold of yield on deposits that is artificially lower than the inflation rate [7, p. 1293]. If $R D R$ turns negative, it means financial repression is tightened, thus stimulating $F R I$ for further growth.

3. Public Debt Holdings by captive audiences (PubDebtH). This indicator equals a percentage of government bonds carried at the balance sheet against total assets of financial institutions, including commercial banks, State-owned banks, pension funds.

This indicator embraces a broader array of financial institutions than those ones included into the concept

\footnotetext{
*Translator's note: In this context, the refinancing rate shall mean the rate of interest charged by the central bank on loans it provides to commercial banks. The calque from the Russian language is given deliberately in this article, for this concept is called differently in various countries (bank rate in the UK, discount rate in the USA, etc.)
} 
of captive audiences. However, it allows tracing the financial repression trend in case government debt securities grow in numbers in a portfolio of the private financial sector.

If the captive audiences appear to hold more government bonds in their accounts, it indicates financial repression is getting invigorated. Therefore, I deal with the reverse value of PubDebtH in my further econometric analysis. The reason is that all constituents of the expected index were homologous in their effect, and the lower indicator would also raise the financial repression index like in other cases.

4. Real Bond Yields (Byields) represent the nominal yield (coupon) of a government bond the national government pays to investors of the public debt, being adjusted for inflation. The government enforces the financial repression policy by setting the nominal yield on bonds below the rate of return on production capital $[8$, p. 33].

The data on the indicator proceed from the Bloomberg trading platform. A decrease in the indicators means financial repression is gaining momentum.

5. Reserve Requirements (ResReq) is the legally stipulated amount of mandatory reserves against banks' liabilities. This rate regulates the amount and structure of the reserve, which may contain cash and highly marketable securities with a long-term low risk (for example, as per the Basel III Accord, government bonds are preferable).

I assume that increased reserve requirements are evidence of financial repression. To ensure a homogeneous effect of all the indicators, I use the inverse value of reserve requirements.

Statistical data I collected for the analyzable period were standardized so to make cross-country figures comparable. The data were standardized using the formula below:

$X_{\text {scaled }}=\left(X-X_{c p}\right) /$ St.dev. $X$,

where $X_{\text {scaled }}$ is the standardized value of the indicator;

$X$ is the original value of the indicator;

$X_{\text {avg. }}$ is the mean value for the period in a certain country;
St.dev. $X$ is the standard deviation of the $X$-sample values.

\section{The Method for Analyzing the Constituents, and Their Characteristics}

Being a part of monetary policy, the selected variables can be analyzed individually or jointly within the financial repression index.

Some researches focus on the effect the artificially lowered real interest rate has on economic growth [9, p. 28-30]. In particular, certain researches prove that financial repression, if represented with negative interest rates, has an adverse effect on economic growth [10, p. 20-22].

Studying each constituent can detect how, say, the negative refinancing rate influences economic growth, but it fails to reliably evaluate the general effect of repressive policies. Assuming that the national government implements financial repression through a set of methods, the regression construction in line with each particular constituent may entail biases due to insufficient parameterization of the model (missing explicative variables).

All the variables within the same regression equation can be presumably more informative. However, certain difficulties arise, since the repression constituents are often mutually related. Furthermore, many analyzable variables constrain a statistical analysis, because respective statistics of some countries are very hard to find for a given period of time.

Therefore, researchers are often ambivalent in choosing the appropriate number of variables to be used and the reliability and accuracy of econometric data and results. This issue can be tackled by forming an analytical, composite index of financial repression. In this research, I build the financial repression index, which would reflect the general impact of all the analyzable tools.

For empirical purposes, I need an index, which, by its nature, represents a set of monetary policy measures [11, p. 43]. I suggest following J.B. Ang and W.J. McKibbin $[12$, p. 222] in applying the Principal Component Analysis method, which was pioneered by P.O. Demetriades, K.B. Luintel [13, p. 460]. The merit of the method is that it addresses the issue of 
multicollinearity and excessive parameterization of the model.

The Principal Component Analysis generally explains the variance of observable data and aligns them in linear combinations, reducing their quantity. Even if there is the $Q$-number of variables, data $x_{1}, x_{2}, x_{3} \ldots x_{Q}$ are dispersed due to the fewer number of variables, or the so called linear relationship of input data $Z_{1}, Z_{2}, Z_{3} \ldots$ $Z_{Q}$, that do not correlate.

In this case, there are five variables $(Q=5)$ and panel data for the 2008-2014 period. At this step of the analysis, there is still the $Q$-number of principal components, i.e. as many as variables [14, p. 39].

The next step is to select one components or several ones so to meet the condition of $P<Q$, where $P$ denotes the number of sampled components. The components must explain the major part of input data variance ${ }^{2}$.

$Z_{1}=a_{11} X_{1}+a_{12} X_{2}+\ldots+a_{1 Q} X_{Q} ;$

$Z_{2}=a_{21} X_{1}+a_{22} X_{2}+\ldots+a_{2 Q} X_{Q} ;$

$\cdots$

$Z_{Q}=a_{Q 1} X_{1}+a_{Q 2} X_{2}+\ldots+a_{Q Q} X_{Q}$

where $a_{i j}$ denotes factor loadings;

$x_{1}, x_{2}, x_{3} \ldots x_{Q}$ are variables;

$Q$ means the quantity of variables.

Zero correlation among principal components is an important property. It indicates the components measure different statistical facets of data.

On the one hand, the Principal Component Analysis turns out to be an appropriate method, if the research aims at presenting a great deal of data and using few variables.

On the other hand, variables can significantly decrease in numbers, if they strongly correlate. This research handles a modest set of data, thus a priori assuming that there is a certain correlation among the five variables.

Weights $a_{i j}$, also called factor loadings and applicable to variables $x_{j}$, are sampled so that principal components $Z_{j}$ meet the following conditions:

1) they do not correlate (orthogonal);

\footnotetext{
${ }^{2}$ Handbook on Constructing Composite Indicators: Methodology and User Guide. OECD, 2008, pp. 63-72.
}

2) the first component accounts for the highest possible percentage of explained values variance; the second component explains the maximum volume of the variance remaining unexplained by the first one; and the process goes on until the entire variance is explained. In this respect,

$a_{i 1}^{2}+a_{i 2}^{2}+\ldots+a_{i Q}^{2}=1,2 \ldots Q$.

The PCA method also involves eigenvalues $\lambda_{j,} j=Q$ of the $\mathrm{cm}$-sample covariance matrix.

The quantity of eigenvalues coincides with that of variables. Some eigenvalues can be disregarded.

Eigenvalues have an important property. Their variance equals that of the variables in question:

$\lambda_{1}+\lambda_{2}+\ldots+\lambda_{Q}=c m_{11}+c m_{22}+\ldots+c m_{Q Q}$.

To prevent one of the variables from exerting an excessive impact on the principal components, variables are usually standardized. The standardization is intended to ensure all the variables have the zero medium and zero unit variance in the beginning of the analysis.

The financial repression index will consist of the five most significant constituents of repression and explain the major part of the respective variance.

The Principal Component Analysis method also allows to evaluate the extent to which a change in one of the tools correlates with the financial repression in each analyzable country [15, p. 764-765].

Based on the assessment, I conclude the sampled countries enforce financial repression policy in their financial sectors.

Afterwards I make up a table to indicate eigenvalues of the correlation matrix for the five individual indicators (standardized values of the variables), which will underlie $F R I$. In total, the eigenvalues equal the number of variables $(Q=5)$.

To set up $F R I$, I estimate its value for each country, in particular. Then the correlation matrix of $F R / s$ is built with respect to all the thirteen countries so to capture all similar trends in monetary policies.

Before the financial repression index is built, the relationship among the five constituent coefficients 
shall be evaluated. Whereas this research analyzes panel data changing spatially and temporally, the correlation matrix is prepared for each country, in particular. The correlation matrices for Japan and Russia are given in Fig. 1 and 2.

It is noteworthy that the figures present an analysis of the 15-year period of observations (2000-2014). While Japan's methods for managing the interest rate, public debt and reserve requirements are substantially interrelated, Russia's coefficient of correlation among the refinancing rate and other measures of monetary policies are almost nonexistent.

Reviewing Japan's monetary policy, I conclude the Japanese government deliberately manipulated the reserve requirements and the refinancing rate so to raise more investment in public debt instruments [16, p. 244-248].

On the one hand, the dependency between the refinancing rate $R I R$ and the amount of public debt held with financial institutions is significant, since the correlation coefficient exceeds 0.5 , being positive. It means the government artificially holds yield on deposits down, thus making the public debt instruments more attractive [17, p. 764].

On the other hand, the Japanese government often undertakes administrative measures to maintain the demand for public debt instruments. It shows the correlation coefficient between the amount of public debt and the reserve requirements.

The Basel Accord is known to equate government bonds and reserve denominated in foreign currency as the most marketable means of savings. That is why financial institutions have to purchase such instruments to pass acid tests. The Japanese government actively sold out public debt instruments to pension funds and commercial banks [18, p. 204-212].

In this respect, it is possible to presume all tools of Japan's monetary policy are rather strongly correlated.

The monetary policy of Russia appears to be an opposite case. If the correlation coefficient among its indicators is analyzed, it approximates zero in the majority of cases. The reason is that the refinancing rate was not intended to foster the economy until 2013, being just a control of money supply in the market.
Analyzing the composition of each country's index is the following step. Although I selected the five most frequent types of monetary policy to address the issue, these measures are not always a sign of the financial repression policy due to the reasons I mentioned.

This assumption is statistically corroborated. Real values of the interest rate and yield on deposits often keep above the negative level.

The correlation matrix of each country's factors was constructed to trace the most crucial correlations among the five tools of monetary policy.

It is possible to single out a group with five or less factors being strongly correlated, and those countries with only two of five analyzable tools demonstrating a correlation.

For ease of analysis, I refer to Brazil, where the interest rate, percentage of public debt held with financial institutions and reserve requirements have high correlation coefficients (Fig. 3).

As the analysis shows, the refinancing rate correlates with the deposit rate and public debt strongly (the coefficients equal 0.9 and -0.91 respectively). The real refinancing rate and reserve requirements also demonstrate a relatively high inverse dependency. I can conclude that four of the five factors can be used to evaluate principal components.

Thus, as the correlation analysis shows in case of Brazil, four of the five financial repression factors strongly correlate and significantly influence trends in the composite index of financial repression.

The findings on the financial repression policy of Brazil do not contravene previous researches, though the significance of the real interest rate has always been higher than other tools of monetary policy [19, p. 411-414].

As the next step, the Principal Component Analysis follows. As a result, I get eigenvalues, component loadings of each factor and form the financial repression index of Brazil.

Fig. 4 displays the eigenvalues of four components that match the number of the most correlating factors. The variance percentage explained by the first 
component is rather high - 81 percent. Fig. 4 shows the eigenvalues of the components.

The first component explains the highest possible percentage of variance of all the individual indicators (Eigenvalue $=3.04$ ).

The second component explains the highest possible percentage of the remaining variance, being equal to 0.68 .

The eigenvalues of the third and fourth components are 0.22 and 0.05 respectively.

The eigenvalue of the second component is below 1 . Hence, it is statistically reasonable to analyze the first component only.

Fig. 5 indicates component loadings for each indicator of financial repression in Brazil. High and medium values of component loadings ( $>0.5$ ) reveal the way certain indicators (standardized values of variables) correlate with the principal components. Negative loadings of PubDebtH- and ResReq-factors expose their feedback effect on the financial repression policy in the country.

\section{The Construction of the Financial Repression Index and An Analysis of Its Composition}

The $F R I$ structure in each country shall be examined in order to find common traits of monetary policy in some countries. Therefore, it is necessary to analyze the sign and value of component loadings measured through the Principal Component Analysis.

For more convenience, I prepare a combined chart of values so to give an illustrative view of common traits among analyzable countries (Table 1).

In addition to Brazil, I attribute China, France, Japan, Israel, the Netherlands, Switzerland to a group of countries with at least three of five factors influencing the FRI trend. Treating this group as a cluster, it is possible to note that the refinancing rate is an important tool of financial repression in all the countries, except for China.

It is no wonder for a group with definite deflationary trends.
Nevertheless, the group sees a different impact of the factors within the FRI structure. In Israel, the public debt placement undermines the effect of financial repression.

On the one hand, the real yield on government bonds has remained positive for the recent ten years, contradicting financial repression criteria. On the other hand, considering the low inflation rate that does not meet the target indicator of the Bank of Israel, the monetary regulator inter alia opted for monetary incentives with respect to quantitative parameters, i.e. negative real yield on the interest and deposit rates ${ }^{3}$.

Japan has the most complete set of monetary policy tools. Its $F R I$ is seriously influenced as a result of manipulating with both the refinancing rate and reserve requirements, and public debt held in the captive audiences' accounts. Loadings of the first component for these factors are $0.4,0.56$ and 0.57 respectively. These indicators are rather high, considering they are applied comprehensively.

Pension funds with conservative investment policies are known to be considerable actors in the financial system of Japan. The Japanese government actively employs the channel for distributing government bonds to financial institutions, thus contributing to significant weight of the factor within the index. Finally, the reserve requirement management is one of the priorities in the financial repression policies as well.

The opposite situation is observed in the countries, where two factors were enough to analyze and reach the high value of the explained variance of the first component. This group of countries includes Canada, Australia, Norway, India, Russia and South Africa.

As the analysis of FRI in the above countries shows, fiscal policy plays a much greater role there, rather than monetary one. The reasons may differ. It may stem from the poor development level of the market in the BRICS countries (India, Russia and South Africa) [20, p.2], while the resource exporting countries with advanced financial markets, such as Norway, Canada

\footnotetext{
${ }^{3}$ OECD Economic Surveys: Israel OECD reports, 2015. URL: https://www.oecd.org/eco/surveys/Israel-Overview-OECD-EconomicSurvey-2016.pdf
} 
and Australia, simply prefer the fiscal policy and use fiscal stabilizers.

\section{The Financial Repression Index in the OECD and BRICS Countries}

This research focuses on the countries that have a different record of using the financial repression policy. While Japan generally utilizes all the tools of monetary policy, the Norwegian government is confined to regulating interest rates only. Nevertheless, there are several traits being common for the analyzable countries.

To identify common trends in the financial policies of the countries, the correlation of the financial repression indices shall be analyzed (Fig. 6). I construct a matrix and identify the countries with the highest correlation coefficient with respect to other countries.

As the data analysis shows, Brazil's FRI strongly correlates with the financial repression policy of France, India, Japan, the Netherlands, Russia and Israel. Please note all the countries within the group implement comprehensive monetary policy.

As expected, the coefficient of financial repression becomes negative on the onset of the global financial and economic crisis. Japan is the most consistent in its policies, since the financial repression policy declines in the smoothest way, while Israel's FRI progresses more abruptly (Fig. 7).

In the BRICS group, the strong correlation dependency is not registered. However, the financial repression index spiked in all the countries, except for Brazil, from 2007 through 2010 and 2013 through 2014 (Fig. 8).

Financial repression tools are broadly practiced in Brazil and India. Loadings of the first component reveal this. However, while India is consistent in its policy on interests rates and government bonds pursuing to reinforce the financial repression index, Brazil has diverging policies on interests rates, on the one hand, and policy on yield on government bonds and reserve requirements, on the other hand.

As the chart shows, the factors debilitating $F R I$ - reserve requirements and yield on bonds - had the strongest effect on the index dynamism as compared with the factors fostering the financial repression. This trend is observed in all the six countries, where the financial repression index gradually declined.

Table 2 specifies the index in a group of countries with a high income level and low public debt (as the main reason for the government to impose the financial repression policy).

The financial repression practices surged in Australia and Canada in the beginning of the $21 \mathrm{st}$ century. However, the financial repression index dropped down to its negative values by the end of the analyzable period. Both countries significantly adhere to the budgetary policy, historically relying upon tools of fiscal policy, rather than monetary one.

The Netherlands is another interesting example. The financial repression index remained negative there throughout the entire analyzable period and jumped before the oil price crash of 2014 (Table 2). The financial repression index of the Netherlands is very sensitive to the real interest rate and reserve requirements. However, these tools are de facto not controlled by the Dutch government, being within the competence of the European Central Bank.

\section{Conclusions}

As a result of this research, I have formed the financial repression index using the Principal Component Analysis. The Principal Component Analysis enables a researcher to determine the weight of five analyzable constituents within the general trends of the financial repression index. As the main conclusion at this step, I should highlight the regulation of the real rates, such as the refinancing rate and deposit rate, as a key aspect of the financial repression. It is evident, considering the simple and expedite nature of the mechanism.

The countries implementing the financial repression policy used various tools to reach the main goal of the policy. Empirical results of the analyzable units considerably range, since the correlation coefficient of the financial repression index of the respective countries is low.

The financial repression policy and its success substantially depend on the performance of financial institutions, which also vary in the development level. 


\section{Table 1}

Combined indicators of factor loadings of the first component

\begin{tabular}{llllll}
\hline Country & RIR & RDR & PubDebtH & Byields & ResReq \\
\hline Australia & 0.61 & 0.68 & -0.41 & 0 & 0 \\
\hline Brazil & 0.55 & 0.52 & -0.53 & 0 & -0.39 \\
\hline Canada & 0.63 & 0.64 & 0 & 0.44 & 0 \\
\hline China & 0.62 & 0.63 & 0 & 0 & 0.47 \\
\hline France & 0.64 & 0 & 0.67 & 0 & -0.37 \\
\hline India & 0.63 & 0.64 & 0.44 & 0.32 & 0 \\
\hline Japan & 0.48 & 0.48 & 0.48 & -0.45 & 0.44 \\
\hline Israel & 0.53 & 0.53 & -0.48 & 0 & 0.66 \\
\hline Netherlands & -0.66 & 0.35 & 0 & 0 & 0 \\
\hline Norway & 0.7 & 0.7 & 0 & 0 & 0.71 \\
\hline Russia & 0 & -0.7 & 0 & 0.7 & 0 \\
\hline South Africa & 0 & 0 & 0.7 & 0 & 0 \\
\hline Switzerland & 0.67 & 0.57 & -0.48 & & \\
\hline
\end{tabular}

Source:Authoring

\section{Table 2}

The financial repression index in high-income countries

\begin{tabular}{llllll}
\hline Year & Australia & Canada & Netherlands & Norway & Switzerland \\
\hline 2000 & 2.23 & 0.43 & -1.17 & 0.14 & 1.31 \\
\hline 2001 & $-0,65$ & 2.08 & 0.06 & 1.3 & 1.37 \\
\hline 2002 & 0.18 & 0.86 & 0.61 & 2.14 & 2.74 \\
\hline 2003 & -0.62 & -0.52 & -0.08 & -0.8 & -0.7 \\
\hline 2004 & 0.34 & -0.88 & -0.71 & -1.16 & -0.34 \\
\hline 2005 & 0.23 & -0.52 & -0.52 & -1.65 & -0.26 \\
\hline 2006 & -0.09 & 1.33 & -0.57 & -1.34 & -2.51 \\
\hline 2007 & 0.41 & 0.74 & -1.16 & 1.14 & -1.38 \\
\hline 2008 & 1.98 & -1.53 & -1.38 & 0.46 & -2.08 \\
\hline 2009 & -2.72 & 3.08 & -0.05 & 1.48 & -0.43 \\
\hline 2010 & 0.51 & -1.69 & -0.37 & -0.71 & 0.79 \\
\hline 2011 & 0.61 & -2.7 & -1.09 & -0.16 & -0.26 \\
\hline 2012 & 0.11 & -0.12 & 0.33 & -0.58 & 0.63 \\
\hline 2013 & -1.58 & 0.54 & 3.1 & -0.58 & 0.09 \\
\hline 2014 & -0.95 & -1.11 & 3 & 0.31 & 1.04 \\
\hline
\end{tabular}

Source:Authoring 


\section{Figure 1}

The correlation matrix of factors in line with standardized indicators of Japan (computer visualization)

$(\mathrm{obs}=15)$

\begin{tabular}{r|rrrrr} 
& RIR & RDR & PubDebtH & Byields & ResReq \\
\hline RIR & 1.0000 & & & & \\
RDR & 1.0000 & 1.0000 & & & \\
PubDebtH & 0.5666 & 0.5666 & 1.0000 & & \\
Byields & 0.4049 & 0.4049 & 0.3636 & 1.0000 & \\
ResReq & 0.4387 & 0.4387 & 0.9089 & 0.3549 & 1.0000
\end{tabular}

Source: Authoring

Figure 2

The correlation matrix of factors in line with standardized indicators of Russia (computer visualization)

$(\mathrm{obs}=15)$

\begin{tabular}{r|rrrrr} 
& RIR & RDR PubDebth & Byields & ResReq \\
\hline RIR & 1.0000 & & & & \\
RDR & 0.3604 & 1.0000 & & & \\
PubDebth & -0.1174 & -0.1432 & 1.0000 & & \\
Byields & -0.1528 & -0.0687 & -0.0819 & 1.0000 & \\
ResReq & -0.0815 & -0.4549 & 0.2810 & -0.1736 & 1.0000
\end{tabular}

Source: Authoring 


\section{Figure 3}

The correlation matrix of factors for Brazil (computer visualization)

$($ obs=15)

\begin{tabular}{r|rrrrr} 
& RIR & DIR PubDebtH & Byields & ResReq \\
\hline RIR & 1.0000 & & & & \\
DIR & 0.9007 & 1.0000 & & & \\
PubDebtH & -0.9141 & -0.7772 & 1.0000 & & \\
Byields & -0.2110 & -0.0392 & 0.0956 & 1.0000 & \\
ResReq & -0.5109 & -0.4471 & 0.4297 & -0.0264 & 1.0000
\end{tabular}

Source: Authoring

\section{Figure 4}

Eigenvalues of the selected components (computer visualization)

Principal components/correlation

Rotation: (unrotated = principal)

Number of obs
Number of comp.
Trace
Rho

Rho

\begin{tabular}{r|rrrr}
\hline Component & Eigenvalue & Difference & Proportion & Cumulative \\
\hline Comp1 & 3.04437 & 2.35663 & 0.7611 & 0.7611 \\
Comp2 & .687733 & .464897 & 0.1719 & 0.9330 \\
Comp3 & .222837 & .177774 & 0.0557 & 0.9887 \\
Comp4 & .0450629 &. & 0.0113 & 1.0000 \\
\hline
\end{tabular}

Source: Authoring 


\section{Figure 5}

Component loadings of financial repression constituents in Brazil (computer visualization)

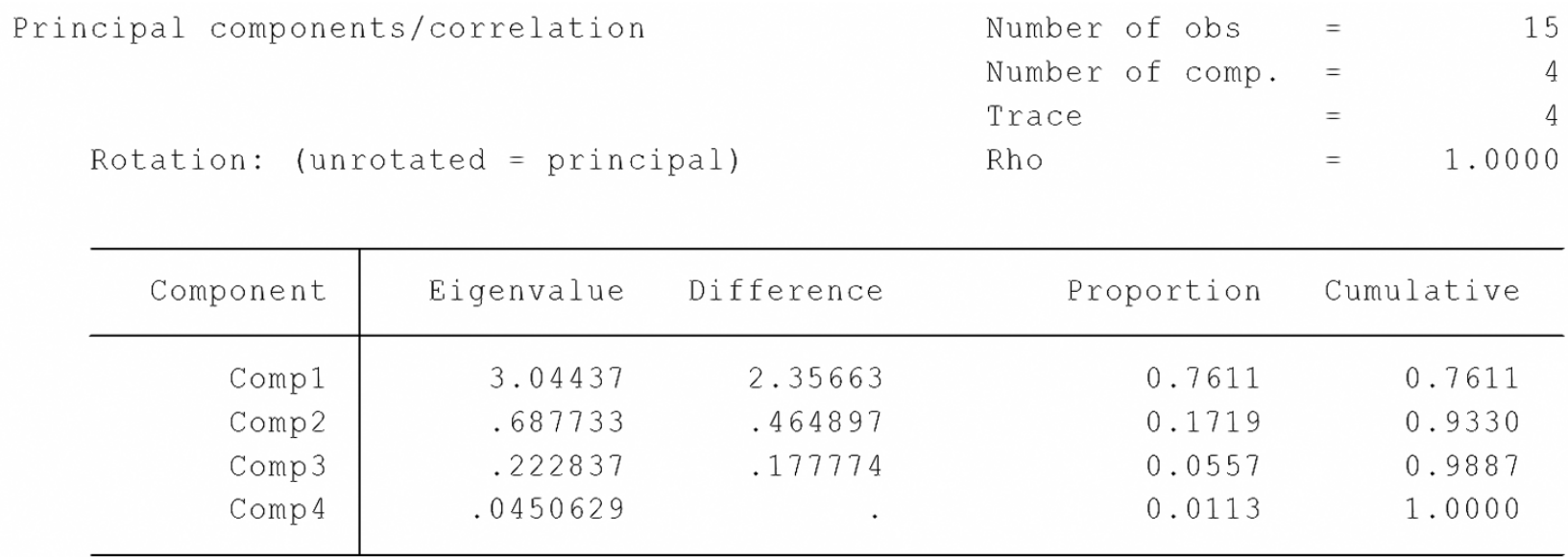

Source: Authoring

\section{Figure 6}

The correlation matrix of financial repression indices for the sampled countries (computer visualization)

(obs=15)

\begin{tabular}{|c|c|c|c|c|c|c|c|c|c|c|c|c|c|}
\hline & FRIAus & FRIBra & FRICan & FRIChn & FRIFra & FRIInd & FRIJpn & FRIIsr & FRINdl & FRINor & FRIRus & FRIZaf & FRIChe \\
\hline FRIAus & 1.0000 & & & & & & & & & & & & \\
\hline FRIBra & 0.3914 & 1.0000 & & & & & & & & & & & \\
\hline FRICan & -0.5253 & 0.2780 & 1.0000 & & & & & & & & & & \\
\hline FRIChn & -0.4128 & 0.2442 & 0.6479 & 1.0000 & & & & & & & & & \\
\hline FRIFra & 0.4038 & 0.8802 & 0.2134 & 0.3593 & 1.0000 & & & & & & & & \\
\hline FRIInd & 0.0095 & 0.6560 & 0.4748 & 0.5731 & 0.6603 & 1.0000 & & & & & & & \\
\hline FRIJpn & 0.3902 & 0.7939 & 0.0697 & 0.4363 & 0.9224 & 0.6154 & 1.0000 & & & & & & \\
\hline FRIIsr & 0.3481 & 0.8009 & 0.1320 & 0.4808 & 0.9199 & 0.6243 & 0.9802 & 1.0000 & & & & & \\
\hline FRINdl & -0.6088 & -0.5387 & 0.1135 & 0.4402 & -0.3614 & -0.0542 & -0.1300 & -0.1242 & 1.0000 & & & & \\
\hline FRINor & -0.1465 & 0.0206 & 0.4529 & 0.4663 & 0.1418 & 0.5024 & -0.0008 & 0.0900 & 0.0499 & 1.0000 & & & \\
\hline FRIRus & 0.3169 & 0.6921 & 0.1630 & 0.2694 & 0.8258 & 0.5886 & 0.7360 & 0.8103 & -0.2657 & 0.3955 & 1.0000 & & \\
\hline FRIZaf & -0.3736 & 0.1221 & 0.5230 & 0.1315 & -0.0116 & 0.4882 & -0.1261 & -0.1282 & 0.0533 & 0.2346 & 0.1023 & 1.0000 & \\
\hline FRIChe & -0.0560 & 0.0349 & 0.0759 & 0.5743 & 0.3094 & 0.2572 & 0.3199 & 0.3640 & 0.3857 & 0.4042 & 0.3764 & -0.1265 & 1.0000 \\
\hline
\end{tabular}

Source: Authoring 


\section{Figure 7}

The index of financial recession, 2000-2014

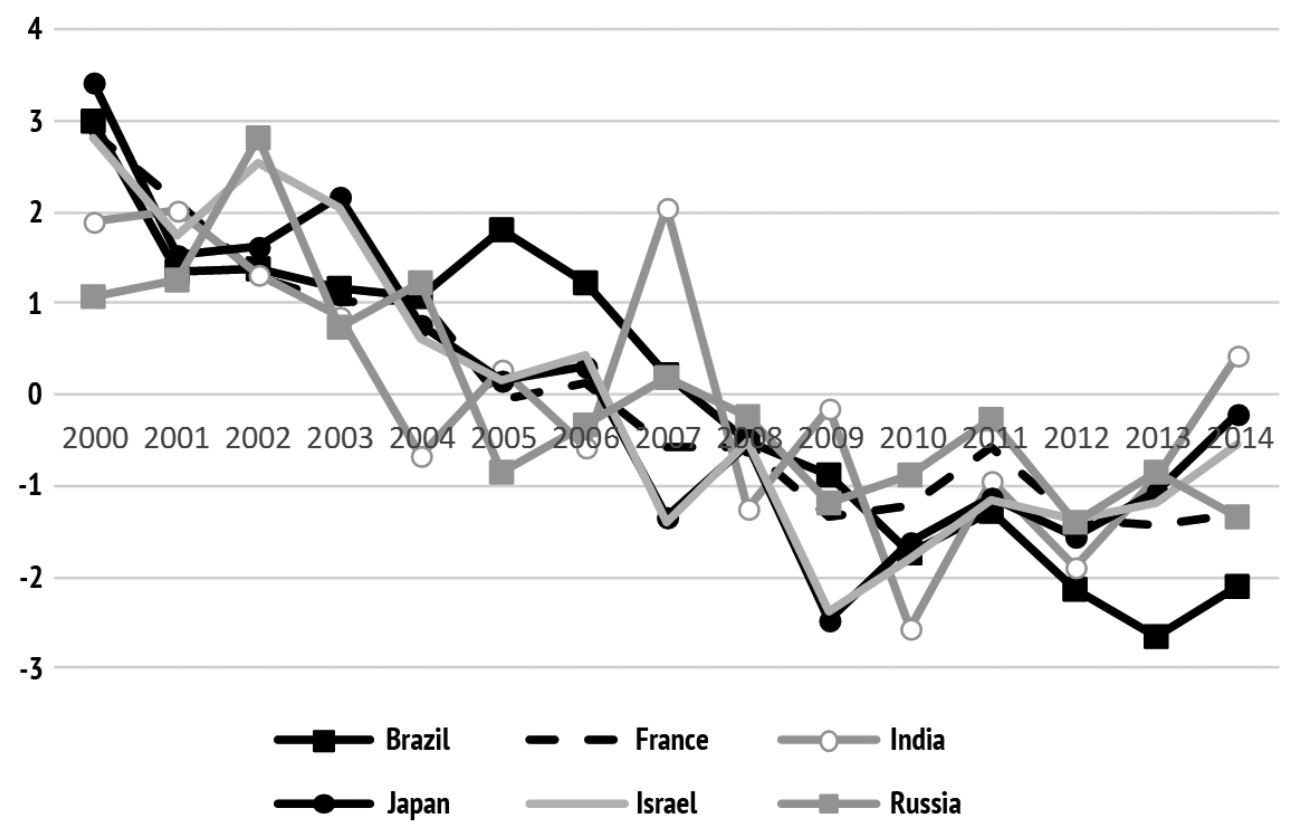

Source: Authoring

\section{Figure 8}

The index of financial recession in the BRICS countries, 2000-2014

$$
4
$$


$-3$



Source: Authoring 


\section{References}

1. Giovannini A., de Melo M. Government Revenue from Financial Repression. The American Economic Review, 1993, vol. 83, no. 4, pp. 953-963. URL: http://www.nber.org/papers/w3604.pdf doi: 10.3386/w3604

2. Reinhart C.M., Kirkegaard J.F., Sbrancia M.B. Financial Repression Redux. International Monetary Fund. Finance \& Development, 2011, vol. 48, iss. 1, pp. 22-27. URL: http://www.imf.org/external/pubs/ft/fandd/2011/06/pdf/reinhart.pdf

3. De Gregorio J. Inflation, Taxation, and Long-Run Growth. Journal of Monetary Economics, 1993, vol. 31, iss. 3, pp. 271-298. URL: https://doi.org/10.1016/0304-3932(93)90049-L

4. Reinhart C.M. Public Debt, Monetary Policy and Financial Stability. Banque de France, Financial Stability Review, 2012, no. 16, pp. 37-48. URL: https://publications.banque-

france.fr/sites/default/files/medias/documents/financial-stability-review-16_2012-04.pdf

5. Drelichman M., Voth H.J. Debt Sustainability in Historical Perspective: The Role of Fiscal Repression. Journal of the European Economic Association, 2008, vol. 6, iss. 2-3, pp. 657-667. URL:

http://www.academia.edu/19836588/DEBT_SUSTAINABILITY_IN_HISTORICAL_ PERSPECTIVE_THE_ROLE_OF_FISCAL_REPRESSION

6. Goswami S., Gupta R. An Endogenous Growth Model of a Financially Repressed Small Open Economy. International Economic Journal, 2009, vol. 23, iss. 1, pp. 143-161.

URL: https://www.deepdyve.com/lp/taylor-francis/an-endogenous-growth-model-of-a-financially-repressedsmall-open-CzTyvvhQ7y

7. Mertens K. Deposit Rate Ceilings and Monetary Transmission in the US. Journal of Monetary Economics, 2008, vol. 55 , iss. 7 , pp. $1290-1302$.

8. Norkina O.A., Pekarskii S.E. [Nonmarket Debt Placement As Financial Repression]. Zhurnal Novoi ekonomicheskoi assotsiatsii = Journal of the New Economic Association, 2015, no. 4, pp. 31-55. (In Russ.)

9. Agarwala R. (CPD). Price Distortions and Growth in Developing Countries (French). Washington, D.C., The World Bank. Staff Working Paper, 1983, no. SWP 575, 92 p.

URL: http://documents.worldbank.org/curated/en/621361468764405568/Price-distortions-and-growth-indeveloping-countries

10. Roubini N., Sala-i-Martin X. Financial Repression and Economic Growth. Journal of Development Economics, 1992, no. 39, iss. 1, pp. 5-30. URL: https://doi.org/10.3386/w3876

11. McKinnon R.I. The Order of Economic Liberalization: Financial Control in the Transition to a Market Economy. Baltimore, Johns Hopkins University Press, 1993, 264 p.

12. Ang J.B., McKibbin W.J. Financial Liberalization, Financial Sector Development and Growth: Evidence from Malaysia. Journal of Development Economics, 2007, vol. 84, iss. 1, pp. 215-233.

13. Demetriades P.O., Luintel K.B. Financial Restraints in the South Korean Miracle. Journal of Development Economics, 2001, vol. 64, iss. 2, pp. 459-479. URL: https://doi.org/10.1016/S0304-3878(00)00146-2

14. Golub G.H., van der Vorst H.A. Eigenvalue Computation in the 20th Century. Journal of Computational and Applied Mathematics, 2000, iss. 123, pp. 35-65. URL: https://doi.org/10.1016/S0377-0427(00)00413-1

15. Feng S., Lu Yang Yao. The Effectiveness of Law, Financial Development, and Economic Growth in an Economy of Financial Repression: Evidence from China. World Development, 2009, vol. 37, iss. 4, pp. 763-777.

URL: https://doi.org/10.1016/j.worlddev.2008.07.018

Please cite this article as: Akhmed Abu Bakr F.A. An Analysis of the Financial Repression Index in the OECD and BRICS Countries. Digest 
16. Ushida M. Towards the End of Deflation in Japan? Monetary Policy under Abenomics and the Role of the Central Bank. Revue de l'OFCE, 2014, vol. 135, iss. 4, pp. 243-268.

URL: http://www.cairn.info/load_pdf.php?ID_ARTICLE=REOF_135_0243

17. Kawai M., Morgan J.P. Long-Term Issues for Fiscal Sustainability in Emerging Asia. Public Policy Review, 2013, vol. 9, no. 4, pp. 751-769. URL: http://www.mof.go.jp/english/pri/publication/pp_review/ppr023/ppr023h.pdf

18. Ogawa K., Imai K. Why Do Commercial Banks Hold Government Bonds? The Case of Japan. Journal of the Japanese and International Economies, 2014, vol. 34, pp. 201-216. URL: https://doi.org/10.1016/j.jjie.2014.07.002

19. Minella A., Souza-Sobrinho N. Monetary Policy Channels in Brazil through the Lens of a Semi-Structural Model. Central Bank of Brazil, Research Department. Working Paper Series, 2009, no. 181, pp. 1-57. URL: http://www.bcb.gov.br/pec/wps/ingl/wps181.pdf

20. Hoffman A., Loeffler A. Low Interest Rate Policy and the Use of Reserve Requirements in Emerging Markets. Universität Leipzig, Wirtschaftswissenschaftliche Fakultät. Working Paper, 2013, no. 120. URL: https://www.econstor.eu/bitstream/10419/74608/1/747342504.pdf

\section{Conflict-of-interest notification}

I, the author of this article, bindingly and explicitly declare of the partial and total lack of actual or potential conflict of interest with any other third party whatsoever, which may arise as a result of the publication of this article. This statement relates to the study, data collection and interpretation, writing and preparation of the article, and the decision to submit the manuscript for publication. 